\title{
CIUDAD LETRADA Y DICTADURA LOS ESPACIOS EN NOCTURNO DE CHILE DE ROBERTO BOLAÑO
}

Paula Aguilar es Professora da Universidade Autónoma de Entre Ríos (Argentina) e investigadora e doutoranda em Literatura Latinoamericana na Universidade Nacional de La Plata - CONICET (Arg).

E-mail: paulaaguilar@conicet.gov.ar

\begin{abstract}
Resumo
O artigo explora a construção dos espaços urbanos no Chile da última ditadura no romance de Roberto Bolaño Nocturno de Chile. A análise indaga o tratamento das cumplicidades, responsabilidades e os medos no interior da 'cidade letrada' que o autor expressa como reflexo de uma sociedade marcada pelo horror do poder ditatorial.
\end{abstract}

\begin{abstract}
Summary
The article explores the representation of urban spaces in Chilean last dictatorship in Roberto Bolaño's Nocturno de Chile. The analysis studies complicity, responsibility and fear in 'the lettered city' as a reflection of a society marked by the horrors of dictatorial power.
\end{abstract}

¿Cómo representar el espacio urbano en dictadura? ¿Qué lógicas recorren la ciudad bajo el dominio del miedo y el terror dictatorial? Intentaremos responder estos interrogantes a partir de la mirada sobre los espacios que Roberto Bolaño ficcionaliza en la novela Nocturno de Chile (Anagrama, 2002).

La dictadura construyó sus propios espacios, en su mayoría ocultos y clandestinos, separados de la cotidianidad. Giorgio Agambem (1995) define el campo de concentración como un estado de excepción, caracterizado por la suspensión del derecho y del ordenamiento normal:

...un lugar aparentemente anodino (...) delimita en realidad un espacio en el que el ordenamiento normal se suspende de hecho y, en el cual, que se cometan o no atrocidades no depende del derecho, sino sólo de la civilización y del sentido ético de la policía que actúa provisionalmente como soberana. (Agamben, 1995, p.3-4)

Sin embargo, estos espacios específicos y ocultos que la dictadura instaura invaden los lugares cotidianos y comunes, contaminan el ritmo de lo normal, se solapan en lo conocido. De este modo los espacios urbanos adquieren una lógica siniestra, todo lugar puede resultar sospechoso o cómplice. Esta nueva disposición espacial puede ser un centro clandestino de detención, el sótano de una casa, la ciudad entera.

Pilar Calveiro (2004) analiza los campos de concentración, en la última dictadura en Argentina, como zonas específicas que terminan contaminado la lógica social bajo el sistema represivo. Los campos de concentración no están apartados y alejados del orden social, por el contrario, su trama configura un entretejido con la sociedad que no es ajena a las prácticas del poder totalitario. La tesis que desarrolla Calveiro nos sirve para pensar los espacios en dictadura en relación con los diferentes 
registros de complicidad social. Expresa la autora: "Nadie puede permanecer en él ‘puro' o intocado; de ahí la falsedad de muchas versiones heroicas. [...] En el mundo de los campos nadie puede atribuirse la inocencia pura ni la culpabilidad absoluta” (2004, p. 159).

En Nocturno de Chile, si bien no aparece el campo de concentración, sus características invaden los espacios representados que develan al Chile de la dictadura como un gran campo donde los límites entre víctimas y victimarios se vuelven difusos, como una gran zona gris (Levi, 1995) ${ }^{1}$ en donde parálisis o complicidad denuncian una sociedad anestesiada, signada por la oscuridad, el silencio y la inmovilidad. ${ }^{2}$

Dos sitios, el fundo Là-Bas de Farewell y la casa de María Canales, funcionan como estos espacios de doble fondo, lugares ambiguos que por un lado se presentan como normales y cotidianos, y por el otro pueden ocultar su complicidad con la arquitectura del terrorismo de Estado. Son dos lugares del arte, representados como esferas ajenas a lo político, donde ocurren episodios que denotan el horror: el fundo frecuentado por el selecto grupo letrado del país y la casa de las veladas artísticas como metáforas del Chile infernal de la dictadura militar. Entonces, Bolaño elige estos espacios de la cultura y del arte para introducirnos en el terrorismo de Estado. Así, se trazan dos topologías, en el fundo Là-Bas y la casa de María Canales, que dan cuenta de los diversos grados de complicidad y responsabilidad de la ciudadanía. En ellos, es la ciudad letrada la que aparece cuestionada, junto con otro importante sector: el eclesiástico.

Al comienzo, Là-Bas se caracteriza como espacio de la cultura, un castillo alejado de la ciudad, cerrado, que corporiza el distanciamiento torremarfilista entre arte y vida (la referencia a Huysmans es explícita) y que denuncia el espacio externo como barbarie. Sin embargo, la imputación cambia paradójicamente de signo con la presencia de marcas simbólicas que relacionan - a modo de antecedente que prefigura - ese espacio cerrado con la dictadura. El poeta y sacerdote Sebastián Urrutia Lacroix, narrador protagonista de la novela, llega a Là-Bas para seguir los pasos de Farewell, el gran crítico de las letras chilenas. En primer lugar, el ingreso al fundo como refugio de la cultura - en un Chile pre-dictatorial, inculto, "país de bárbaros"- aparece como un descenso a los infiernos, formando parte de una etapa iniciática en la conversión del cura Urrutia Lacroix en el crítico literario Ibacache, "Como si aquel carricoche fuera a buscar a alguien para llevarlo al infierno" (18). ${ }^{3}$ En su interior la sala principal "se asemejaba a una biblioteca y a un pabellón de caza, con muchas estanterías llenas de enciclopedias y diccionarios (...) amén de por lo menos una docena de cabezas disecadas” (19). La casona funciona como fantasmagoría. Es el interior confortable aislado del peligroso mundo del afuera.

En "Estética y anestésica: una reconsideración del ensayo sobre la obra de arte", Susan Buck-Morss indaga la crisis de la percepción como fenómeno anestésico, contraparte de la noción benjaminiana de shock. En la sociedad moderna, el pasaje de la estética (la sensibilidad) a la anestésica (la pérdida de sensibilidad) provoca una incapacidad de reflexión consciente ante la realidad que circunda. La percepción, 
bombardeada por estímulos repetitivos, no logra anclarse en experiencia, como señala Buck-Morss "el sistema [sinestésico] invierte su rol. Su objetivo es adormecer el organismo, retardar los sentidos, reprimir la memoria: el sistema cognitivo de lo sinestésico ha devenido un sistema anestésico" (Buck-Morss, 2005, p. 190). En este contexto, los interiores burgueses del siglo XIX ofrecen una tranquilidad engañosa a los sentidos a través de los denominados “efectos fantasmagóricos” (Buck-Morss, p. 196). Así, Là-Bas, con todo el imaginario decadente que despliega, funciona como una gran burbuja que adormece el sensorium del cura, es un "mundo de ensueño privatizado (...) escudo protector para los sentidos y las sensibilidades” (Buck-Morss, p. 196) que choca contra la naturaleza y la fresca cotidianidad de los campesinos. Sebastián asiste a los banquetes que el crítico literario Farewell ofrece en la finca. En dos ocasiones, el cura recorre el exterior del fundo Là-Bas y se encuentra con los campesinos y con los niños que generan "miedo y asco" (20) en tanto parte de un 'afuera' irreducible, inclasificable y caótico. El sacerdote no comprende sus acciones, su discurso se vuelve dubitativo, repetitivo en imágenes, interrogador, dice: “consiguieron alterar mi equilibrio mental y físico” (30); “...todos eran feos. Las campesinas eran feas y sus palabras incoherentes. El campesino era feo y su inmovilidad incoherente. Los campesinos que se alejaban eran feos y su singladura en zigzag incoherente.” (30) Cada paseo por las afueras del fundo se describe en términos de extravío, de contaminación: la naturaleza salvaje, la presencia del otro - como ya se mencionó - provocan miedo y asco.

Hay en Là-Bas la confrontación de dos espacios - uno, desestabilizador; el otro, reconfortante y estable - cuyos límites, sin embargo, se tornan difusos; por momentos lo seguro se vuelve confuso. Luego de uno de los paseos del cura por las afueras de LàBas, donde comparte el pan duro de los campesinos, "manjar ambrosiano, deleitable fruto de la patria, buen sustento de nuestros esforzados labriegos” (22), se describe una cena, a modo de gran banquete, con importantes invitados - Pablo Neruda, entre ellos. Esta situación al sacerdote le produce nauseas, se siente enfermo y su discurso incurre en el delirio y la incoherencia vertiginosa: una conversación con Farewell que delata sus inclinaciones homosexuales, un 'diálogo de locos' con Neruda, escenas que descolocan al cura quien, no obstante, expresa: “y recuerdo que en aquel momento yo tuve conciencia de mi miedo, aunque preferí seguir mirando la luna” (26). El cura no puede reaccionar, los efectos de una realidad narcotizada amalgaman el espacio interior con el exterior.

Pero en Nocturno de Chile el trauma de la experiencia no está provocado por la vida moderna, técnica e industrial. Está más cercano a las consecuencias estudiadas por Freud en "Más allá del principio del placer" 4 que Benjamin utiliza como intertexto. La violencia del campo de batalla se resignifica en la novela con la violencia agazapada de la dictadura militar. Las redes que el orden y el poder dictatorial traman infiltran la vida cotidiana de una sociedad que, adormecida, pretende sobrevivir. A través de oposiciones, como lo impuro y lo puro, lo sucio y lo limpio, lo culpable y lo inocente, la novela va a mostrar los dobleces de una realidad 'construida', para delatar las zonas que 
la apariencia quiere ocultar, así como los centros clandestinos de tortura intentaban camuflarse en los espacios de una ciudad militarizada.

Así, esta duplicación confusa (afuera/adentro; cultura/barbarie) prefigura la simultaneidad espacial que tendrán la sala de tertulias y el sótano del horror bajo el mismo techo de la casa de María Canales. Allí, se describe el final de las reuniones de la siguiente manera: "uno de nosotros previamente se había encargado de abrir el portón de hierro, y María Canales seguía en pie en el porche hasta que el último auto trasponía los límites de su casa, los límites de su castillo hospitalario” (128, cursivas nuestras), detalles que remiten al fundo de Farewell, que aparece, así, como prefiguración del Chile de la dictadura.

La casa de María Canales también posee una estructura interna dual. La simultaneidad de las tertulias literarias con la sala de tortura denuncia un Chile 'de superficie’ y otro ‘de sótano’ e indaga acerca de las complicidades silenciosas -hasta inconscientes- con el régimen militar. De igual forma, demuestra como el refugio que ofrece el espacio de la casa de Canales no es más que una ilusión. Aquí, el círculo intelectual no está conformado por aristócratas torremarfilistas, pues las tertulias reunían a un número de "intelectuales dispuestos a crear de la nada (...) la nueva escena chilena" (129, cursivas nuestras): un poeta desesperado, una novelista feminista, un pintor de vanguardia hablan de literatura mientras el sótano funciona como sala de tortura.

Patricia Espinosa señala que puede leerse:

"un calco casi exacto entre el poder político y el poder crítico. Este espejeo, sumado a las tertulias en la casa de María Canales, en cuyos subterráneos se practicaba la tortura, tiende a abrir una brecha culposa en la moralidad del establishment artístico nacional” (Espinosa, 2002, p. 131).

Es necesario preguntarnos acerca de ese "establishment artístico nacional" que Bolaño está poniendo en cuestión. No sólo involucra a los sectores intelectuales afines a la dictadura sino que se abre a un espectro más amplio de artistas. Incluso podríamos sospechar que, provocativamente, hay una referencia a la hipervanguardia, que reunió a un grupo de artistas quienes durante el gobierno de Pinochet constituyeron lo que Nelly Richard (1994) denominó ‘el polo victimado’, como escena cultural alternativa y crítica de la crisis dictatorial. Esa dualidad representada en la casa de María Canales socava toda posibilidad real de resistencia o crítica, con lo que Bolaño interpela - sin reparos al sector más progresista del campo intelectual por algún grado de complicidad o al menos silencio con las políticas del terrorismo de Estado.

Una vez terminada la dictadura, se dan cuatro versiones del episodio de la tortura; cada una agrega nuevos datos como parte de un proceso de recuperación de la memoria que crece con la apertura democrática - en un despliegue de sucesos, de información que devela y obstruye, avanza y se paraliza. El cura se encuentra con un 
“joven novelista de izquierda” quien niega repetidas veces haber conocido a María Canales o participado de las reuniones y nos retrotrae al momento en que el cura prefirió mirar la luna en Là-Bas, sin hacerse cargo de un contexto agobiante. Si, en un primer momento, el foco está puesto en la élite literaria, opusdeísta, pasando aún por el mismo Neruda, aquí la sospecha involucra a los escritores más progresistas de la escena chilena. Al respecto, Hugo Vezzetti expresa que "una sociedad debería hacerse cargo no sólo por lo que activamente promovió y apoyó sino incluso por aquello que fue incapaz de evitar" (2002, p. 41).

Así, el círculo aislado de Là-Bas, y luego las tertulias, constituyen zonas que la novela va a ir delineando - y cuestionando - en relación con los diferentes lugares de escritor en el marco dictatorial. También se diseña una cierta topología de 'colaboracionismo silente' con la dictadura a través de los elementos recurrentes que remiten a la simbología cristiana por medio de imágenes de la traición y la culpa: la figura de Pedro y de Judas, la cena, el árbol: "Chile entero se había convertido en el árbol de Judas, un árbol sin hojas, aparentemente muerto” (138).

Ese engranaje que conforman el campo cultural y el poder dictatorial ya se anticipa en la primera misión que los señores Oido y Odeim le encomiendan al sacerdote; los mismos que en los años de ‘odio' y 'miedo' dictatoriales le piden que enseñe marxismo a la Junta Militar. Pero esta primera misión implica a la institución eclesiástica.

El cura viaja a Europa, a pedido de la casa de Estudios del Arzobispado, para revelar datos sobre la conservación de iglesias; allí aprende que su mayor problema son las palomas (su excremento) y la solución, los halcones adiestrados por los curas para destruirlas. Esta anécdota se resignifica con los sueños del cura que perturban y alumbran otras lecturas de lo narrado. En el sueño, "veía una bandada de halcones, miles de halcones que volaban a gran altura por encima del océano Atlántico, en dirección a América” (95).

El horror que se instalará en Chile con el Golpe se desplaza a América Latina en el cruce de referencias que, ahora, aluden al horror pero en México, país que es otra constante en la narrativa de Bolaño. Los "Halcones" remiten directamente al grupo represivo que entre 1966 y 1971 integraron alrededor de mil agentes armados. Este grupo paramilitar, fundado por el coronel Manuel Díaz Escobar, participó de la masacre de Tlatelolco, el 2 de octubre de 1968; el mismo Bolaño afirmó haber sido joven testigo de esta matanza de estudiantes durante su residencia en México. ${ }^{5}$ Díaz Escobar fue trasladado como agregado militar a Chile, poco antes del golpe de Estado del 11 de septiembre de $1973 .{ }^{6}$ La novela de Enrique Lafourcade, dos veces mencionada, Palomita blanca (1971), también es iluminadora: el intertexto funciona como articulador; recordemos los títulos de sus últimos capítulos: "Palomita negra, vidalita de piquito rojo crece palomita, vidalita y volvete halcón”. Los sesenta y setenta allendistas que la novela escenifica como marco de referencias ya no son válidos, especialmente en el contexto de unas clases de marxismo que el sacerdote da a Pinochet y otros altos miembros del gobierno militar. Pinochet reconoce que leyó la novela y la 
comenta ("tampoco es para tanto" dice); las palomas transformadas en halcones sobrevuelan un Chile negro.

Otro episodio que articula este espejeo entre Europa y América Latina signadas por la violencia es narrado en el relato intercalado de Jünger y el pintor guatemalteco. En Europa, el cura conoce al escritor Ernst Jünger quien le relata una extraña historia sobre un pintor guatemalteco en Paris. En el marco opresivo de la Segunda Guerra Mundial, el artista latinoamericano pasa sus días encerrado en una pequeña habitación francesa con la única 'actividad' de contemplar la ciudad a través de la ventana. ${ }^{7}$ Claro exponente del morbus melancholicus burtoniano, ${ }^{8}$ el pintor es víctima de una aplastante inanición y hastío, ha desarrollado una "segunda conciencia” en la que el cuerpo se vuelve inerme al dolor (Jünger, citado por Buck-Morss, 2005, p. 210) para protegerse de un contexto pavoroso. Melancolía o actitud blasée, que para Georg Simmel define el estado de "insensibilidad ante las diferencias de las cosas" (2005, p. 4) producto de la “intensificación del estímulo nervioso" en la vida urbana. El pintor guatemalteco no observa la metrópolis francesa del siglo XIX, sino una París de persecuciones, invadida por el nazismo. En este cruce reflexivo en torno al mal y la violencia no es casual que esa condición del pintor se refleje en su única obra, un cuadro que muestra a la ciudad de México una hora antes del amanecer: barrios como negativos de fotografías y esqueletos difusos. Uno de los rasgos que la tradición melancólica destaca es el de la lucidez ${ }^{9}$ : desde Aristóteles la condición melancólica revela el genio de un ser lúcido cuyo saber se vuelve inútil ante la negatividad de su entorno, reflejo de su alma. La lucidez del guatemalteco sólo le sirve para aceptar "la derrota de sí mismo” (62).

La diseminación de tópicos que aluden al tedio, la inacción, lo funeral, la muerte sustenta una narrativa que es el reverso de un arte optimista o de tintes heroicos, que pauta el fracaso de los grandes relatos, y que nos entrega como símbolos del presente: el nocturno, la melancolía y el crepúsculo.

El sacerdote representa lo que Nelly Richard (2003) llama "figura del trauma, el duelo y la melancolía”, original ficcionalización de alguien que intenta suturar el quiebre interno de una identidad que se creía sólida; hacer un mea culpa que deviene imposibilidad y lo revela como alguien capaz de ejercer un tipo de acción que lo constituye en cómplice directo y articulador de la política dictatorial. Así, víctimas y verdugos, sin llegar a ser idénticos ni confundirse, se entremezclan en esa "zona gris" que describió Primo Levi para referirse a la identificación de las víctimas con los victimarios, ese espacio que los separa y reúne a la vez en la vida cotidiana del campo. Lo mismo vale para los letrados que, aún sin saberlo, compartían veladas artísticas con el horror de la tortura. Bolaño desenmascara la responsabilidad de cada uno de nosotros por nuestros actos ${ }^{10} \mathrm{y}$ denuncia un escenario postdicatorial orientado a reconciliar $\mathrm{y}$ negociar.

Violencia y complicidad en la ciudad letrada y en la Iglesia: los curas entrenaban halcones para matar a las palomas y el cura Ibacache enseña marxismo a Pinochet "para comprender a los enemigos de Chile, para saber cómo piensan, para imaginar hasta dónde están a punto de llegar” (118). Aquí se revela lo que Gonzalo Aguilar (2001) 
denomina "las oscuras relaciones entre el arte y la barbarie”. Al mismo tiempo, las representaciones del espacio muestran la necesidad de refugiarse en la aparente seguridad de fundos y casas como espacios cerrados a la realidad dictatorial, como si el confinamiento aparentara seguridad y estabilidad cuando en verdad sólo reproduce el mapa de una ciudad ahogada por el horror, el miedo y el silencio. 


\footnotetext{
${ }^{1}$ El concepto es de Primo Levi, Los hundidos y los salvados, Barcelona, Muchnik, 1995. Ver también Vezetti, Hugo, "Representaciones de los campos de concentración en la Argentina”, Punto de vista 68, diciembre de 2000, pp. 1317.

${ }^{2}$ Con estos tres últimos sustantivos describe Calveiro al campo de concentración, (2004, p. 48).

${ }^{3}$ Roberto Bolaño. Nocturno de Chile. Barcelona: Anagrama, 2000. Todas las citas pertenecen a esta edición, se indica número de página entre paréntesis.

${ }^{4}$ Cf. también Benjamin, Walter, "El narrador. Consideraciones sobre la obra de Nicolai Leskov", en: Sobre el programa de la filosofía futura. Barcelona, Planeta-Agostini, 1986, pp. 189-211.

${ }^{5}$ Recordamos Amuleto (1999): Auxilio Lacouture se encuentra encerrada en un baño de la Universidad de México UNAM en 1968 para esconderse de los militares que irrumpen la autonomía universitaria y anticipan ese otro suceso clave: la masacre de Tlatelolco. Aquí, Bolaño narra los procesos de configuración y significación de una memoria traumática a partir de un acontecimiento que funciona como paradigma y metonimia del horror latinoamericano: Tlatelolco como emblema de una generación mexicana que pasa a ser paradigma de una generación latinoamericana.

${ }^{6}$ La imagen paloma/halcón en relación a las dictaduras militares es una constante. En Argentina se utilizaron los términos para distinguir dos facciones dentro de las Fuerzas Armadas: los 'blandos' o ‘palomas' y 'los duros' o 'halcones'. Aquí, en cambio, las palomas remiten a las víctimas de la dictadura.

${ }^{7}$ Sobre la imagen del observador en la ventana como matriz recurrente para leer la ciudad desde la literatura ver Renato Cordeiro Gomes, "De rua e de janela”, SEMEAR 6 Revista da Cátedra Padre António Vieira de Estudos Portugueses da Puc-Rio, 2002 (en línea: http://www.letras.puc-rio.br/catedra/revista)

${ }^{8}$ Es, dice Burton, un mal que se origina en la imaginación, de ahí trasciende a la razón y al corazón, y luego a otras partes del cuerpo como el estómago, el hígado y el bazo. El estado de melancolía se caracteriza por sentimientos como la tristeza y el miedo, que, convertidos en hábitos, pueden llegar a ocasionar la muerte. Una permanente angustia del alma; desvaríos en el discernimiento y la voluntad; pérdida de la razón; alteraciones en la facultad de expresión; desvaríos en las opiniones y las creencias, temor, tristeza y aflicción sin causa aparente, son algunos de los estados que caracterizan al ente melancólico. Robert Burton, Anatomía de la melancolía, [1621], Buenos Aires, Espasa Calpe, 1947.

${ }^{9}$ Simmel, respecto de la actitud blasée, también señala el "florecimiento intelectual en la metrópoli. Es por esto que la gente estúpida que no está viva intelectualmente no es precisamente blasée”.

10 “Quítese la peluca” declama el epígrafe de la novela.
}

\section{Bibliografía}

AGAMBEM, Giorgio. “¿Qué es un campo?”. In Revista Sibila, número 1, enero de 1995 (En http://www.elcultural.com/eva/literarias/agamben)

AGUILAR, Gonzalo. “Los amuletos salvajes de un novelista” Suplemento Cultura y Nación, Clarín. Buenos Aires: 25/03/01.

BENJAMIN, Walter. "Tesis de filosofía de la historia”. In Para una crítica de la violencia y otros ensayos. Madrid: Taurus, 1991.

BOLAÑO, Roberto. “Discurso de Caracas (Venezuela)” (1999). Leído en la entrega del premio Rómulo Gallegos. Publicado en Entre paréntesis. Barcelona: Anagrama, 2004. ---. "Entre el juego y el olvido”. Entrevista de Silvia Adela Kohan para La Nación (Buenos Aires). Barcelona, 25/04/01.

---. Nocturno de Chile, Barcelona: Anagrama, 2002.

BUCK-MORSS, Susan. "Estética y anestésica” y "La ciudad como mundo de ensueño y de catástrofe”. In Walter Benjamin, escritor revolucionario. Buenos Aires: Interzona, 2005. 
CALVEIRO, Pilar. Poder y desaparición: los campos de concentración en Argentina. Buenos Aires: Colihue, 2004.

ESPINOSA, Patricia. “Roberto Bolaño: un territorio por armar”. Celina Manzoni editora. Roberto Bolaño: la escritura como tauromaquia. Buenos Aires: Corregidor, 2002.

LEVI, Primo. Los hundidos y los salvados. Barcelona: Muchnik, 1995.

RICHARD, Nelly.---. La insubordinación de los signos. Santiago: Cuarto Propio, 1994.

---. “Las reconfiguraciones del pensamiento crítico en la postdictadura”. In Heterotropías: narrativas de identidad y alteridad latinoamericanas. Carlos Jaúregui, Juan Pablo Dabove editores. Pittsburgh: Biblioteca de América, 2003.

---. “Lo político y lo crítico en el arte: ¿quién le teme a la neovanguardia?”. pensamiento de los CONFINES número 15, diciembre 2004. Buenos Aires: Fondo de Cultura Económica, 2004.

SIMMEL, Georg, “La metrópolis y la vida mental” (1903). En Bifurcaciones, número 4, primavera 2005 (www.bifurcaaciones.cl)

VEZZETTI, Hugo. Pasado y presente. Buenos Aires: Siglo XXI, 2002. 